\title{
A Survey and Analysis of Scholarly Literature in DEA Published by Croatian Researchers: 1978 - 2018*
}

\author{
Luka Neralic ${ }^{* *}$ \\ Margareta Gardijan Kedžo ${ }^{* * *}$
}

\begin{abstract}
After its introduction in 1978, Data Envelopment Analysis (DEA) has instantly been recognized as a useful methodology for measuring the relative efficiency of different entities, called Decision Making Units (DMUs), given multiple criteria. Up until nowadays, the popularity of DEA has been growing and a significant number of bibliographical items was published, reporting on both theoretical and empirical results. However, the main applicative area of DEA remained the performance measurement in economics and business. On the $40^{\text {th }}$ anniversary of DEA, the aim of this paper is to present the DEA bibliography of Croatian scientists (up until June 2018). We consider six main categories of DEA-related publications, followed with key statistics and an overview of keywords and research areas. The whole list of DEA-related publications used in this analysis is published online. We believe this research will shed light on the state of DEA in Croatian science and motivate future researches.
\end{abstract}

Keywords: data envelopment analysis; efficiency; Croatian science; bibliography; survey

JEL Classification: $\mathrm{C} 83, \mathrm{C} 44, \mathrm{C} 6$

\section{Introduction}

Data envelopment analysis (DEA) is a non-parametric method for evaluating the relative efficiency of units under assessment, called the Decision Making Units (DMUs) given multiple criteria (Lukač and Neralić, 2012: 19). It was introduced in 1978 in the

\footnotetext{
* The paper was presented at the $17^{\text {th }}$ International Conference on Operational Research KOI 2018, September $26-28,2018$, in a special session devoted to the $40^{\text {th }}$ anniversary of establishing DEA.

${ }^{* *}$ Luka Neralić is Professor Emeritus at the University of Zagreb, Faculty of Economics and Business, Zagreb, Croatia.

${ }_{* * * *}$ Margareta Gardijan Kedžo is at University of Zagreb, Faculty of Economics and Business, Zagreb, Croatia.
} 
groundbreaking paper Measuring the efficiency of decision making units by Charnes, A, Cooper, W. W., Rhodes E., which was published in European Journal of Operational Research, 2 (6) (Charnes, Cooper and Rhodes, 1978). Although DEA was initially developed as a tool for evaluating the efficiency of the production units which produce a real output using real inputs, the method found its application in many different problems where the DMUs can be of a different nature. DEA theory developed in line with the extension of the applicative area of the method in order to facilitate the applicative needs and initiate new applications. Nowadays, 40 years after its introduction, we can witness that DEA is an extremely popular method in many areas and its popularity is still growing (Emrouznejad and Yang, 2018). The possible reasons are the simplicity of the method and the fact that DEA is frequently linked and applied in combination with other methodologies. Moreover, the popularity should be owned to the development of the theoretical background, which certainly extended the application of DEA for different problems, as well as to the availability of ready-made DEA software. Since 1978, DEA has gained a lot of attention and a vast number of contributing papers, books, and other bibliographical items were published in both DEA theory and practice. The analysis of the international DEA bibliography was presented in several papers, as it will be explained in the following chapter of this paper.

Motivated by the $40^{\text {th }}$ anniversary of DEA, the aim of this research was to create and analyze the database of DEA literature written / co-authored by the Croatian authors. We based our search on Croatian scientists who are registered in the Croatian scientific bibliography (CROSBI). However, we included Croatian researchers who co-authored a relevant DEA-related publication listed in the database but who were not registered as scientists in CROSBI. The created Croatian DEA database includes 6 types of publications and a group 'other', published in the period of 1987 - May 2018. The database is publicly available on website sites.google.com/net.efzg.hr/dea. The main sources of information for our database were the Croatian scientific bibliography (CROSBI), portal of Croatian scientific journals (HRCAK), Web of Science, website www.deazone, web search and the direct communication with the contributing authors. This paper presents the key statistics of the collected DEA bibliography.

The paper is structured as follows. The $2^{\text {nd }}$ Section presents some of the previously published DEA bibliographies and their surveys. In the $3^{\text {rd }}$ Section, we present our research methodology as well as the key statistics of the database. Section 4 gives the conclusions and discusses possible limitations and future research.

\section{International DEA bibliography}

Several publications give an overview of the DEA literature written by international authors. Some of them provide just a list of the DEA-related publications that meet certain criteria (like a certain type of publication or a citation database). The other 
group of papers contains the analysis of of the databases as well. First publication of this kind was Seiford (1994) that compiled 472 published articles and dissertations related to DEA in the period of 1978 - 1992. A few years later, Emrouznejad and Thanassoulis (1996a, 1996b, 1997) enlarged this database in a series of their working papers and Seiford (1997) provided a list of approximately 800 published articles and dissertations related to DEA in the period of 1978 - 1996, including some useful key statistics. Tavares (2002) presented a database consisting of 3203 publications written by 2152 distinct authors in the period of 1978 -2001, including seven types of publication: event papers, journal papers, dissertations, book chapters, research papers, books and special journal editions related to DEA. He also provided some key statistics of this database concerning the number of publications in the field of DEA, in which Croatia was ranked as the $20^{\text {th }}$ out of 49 countries. Since at that time only 49 countries have been introduced in the DEA bibliography, and given the population size of Croatia and consequently the number of its scientists, this rank was a huge success for Croatian science. The survey and the analysis of the first 30 years of the scholarly literature in DEA were provided in Emrouznejad, Parker, and Tavares (2008). The paper is actually concentrated on the analysis of the DEA literature and the projections of the future trends in DEA, while the database is provided as a supplement. Most recently updated general DEA database and its analysis are published in Emrouznejad and Yang (2018). The database includes a previously collected list of journal papers from the website www.deazone and from the SCOPUS database. Our paper follows the structure of Emrouznejad and Yang (2018), mainly for the sake of comparability. However, our research includes different types of publications, not just journal papers. Lastly, there are papers analyzing the DEA-related literature in a specific research area. For example, Mardani et al. (2018) created and analyzed the DEA bibliography related to the assessment of environmental and energy economics. They limit their search to the citation bases Web of Science (WoS) and Scopus listed articles.

\section{Research methodology and findings}

Information about the Croatian DEA-related literature was collected from the Croatian scientific bibliography (CROSBI), Web of Science (WoS), portal of Croatian scientific journals (HRCAK), website www.deazone, web search and the direct communication with the contributing authors. The keywords used for the database search were data envelopment analysis, CCR model, BCC model, Malmquist, efficiency, etc. We managed to find altogether 176 publications, including the following types of publication: scientific papers, professional (technical) papers, Ph.D. thesis, Master thesis, book or book chapters, and monographs. Some unclassified publications, popular papers and other types of publications are classified as 'other'. We did not include conference abstracts. The rest of this section presents the key statistics of the Croatian DEA bibliography. 
The first DEA-related paper co-authored by a Croatian author was Charnes and Neralić (1987), published in the Proceedings of the XIV. Yugoslav Symposium on Operational Research SYM-OP-IS ‘87, held in Herceg Novi. In the period from 1987 to the end of May 2018, 176 publications were published. Figure 1 shows the distribution and a total number of DEA-related publications in Croatia since 1987.

Figure 1: The distribution (bar chart; primary axis) and a total number (line chart; secondary axis) of DEA-related publications in Croatia (1987-5/2018)

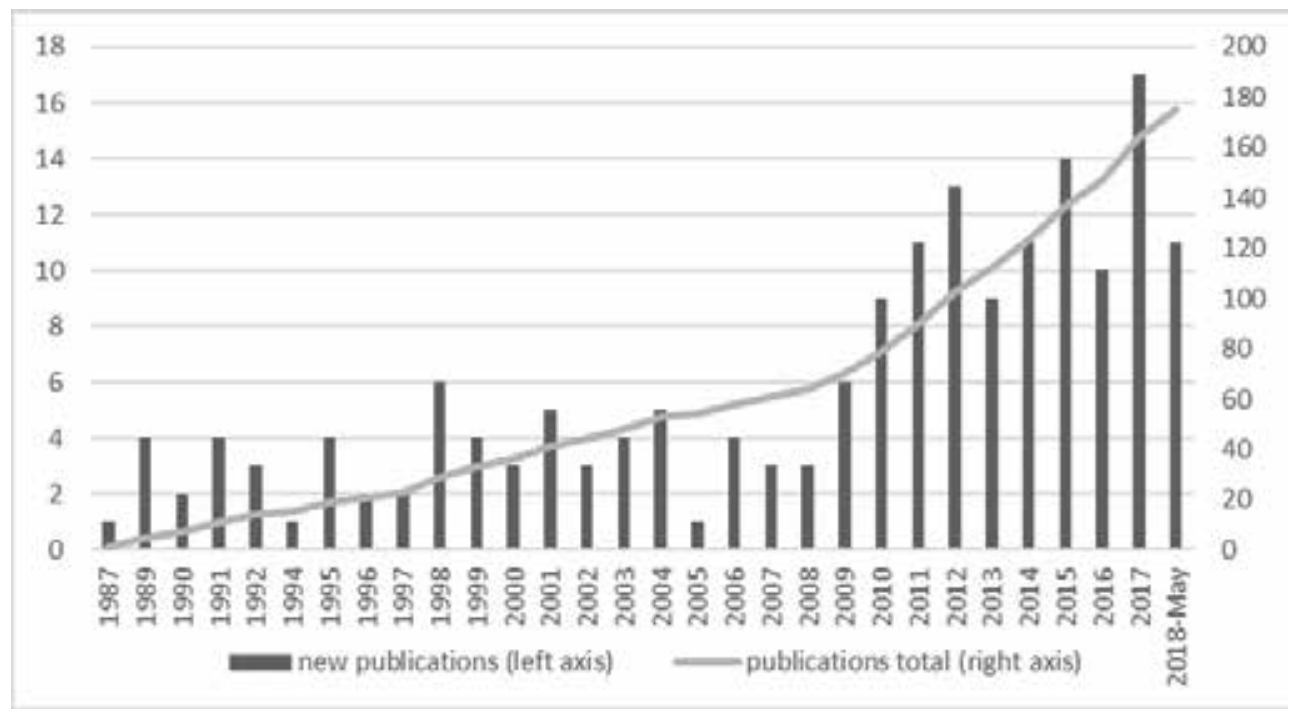

Source: authors

By observing Figure 1, we recognize 3 sub-periods of publication. The first period was 1987-1997, with an average of 2.56 publications per year (min. 1 to max. 4 publications per year). In the second period of 1998-2008, the minimal number of publications per year was 3 (except the year 2005), thus increasing the average number of new publications for that period to 3.72 per year. The third period is 2009-2018, in which we notice an even more increased growth rate in DEA-publishing. In this last period, the average number of publication was 11.56 per year, with a minimum of 6 and a maximum of 17 publications per year.

By comparing Figure 1 with the international trends in DEA journal publishing (which accounts for the greatest share in total publishing), shown in Figure 2, we see that international DEA-publishing started an increased growth in 2004 and Croatia lags behind the international trends for several years. However, 2009 was a breaking year for rocketing DEA publishing in both Croatia and on the international level. The obvious upward trend in DEA publishing in Croatia puts a lot of optimism for 
Croatian DEA-related science as well as motivation for following the growth rate on the international level.

Figure 2: Distribution of DEA-related articles on an international level, by year (1978-2016)

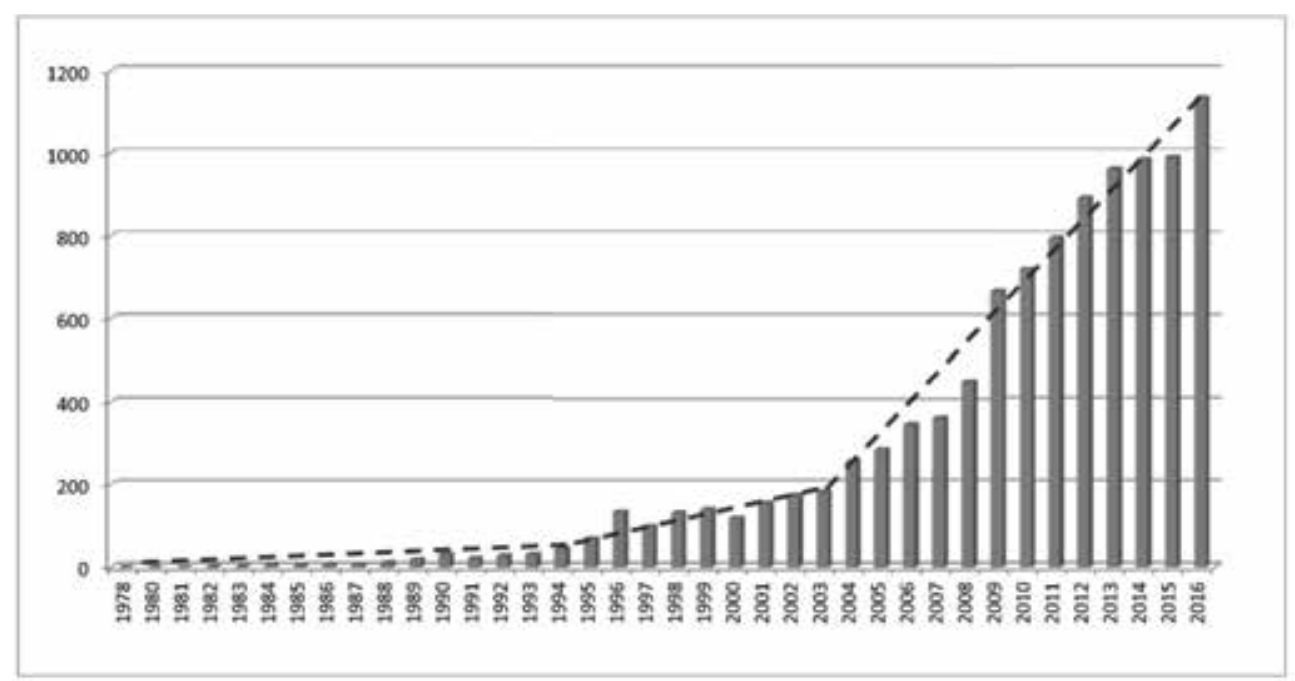

Source: Emrouznejad and Yang (2018)

Regarding the type of the publication, there are 133 scientific papers (75.6\%) and 4 professional papers (2.3\%) in Croatian DEA bibliography. Among them, 52 scientific papers and 1 professional paper were published in full in various conference proceedings (29.5\%). There are $13 \mathrm{Ph} . \mathrm{D}$. thesis and 13 book chapters $(7.4 \%$ each), 4 master thesis (2.3\%), 1 monograph (0.6\%) and 8 other publications (4.5\%) (Figure 3). Obviously, there are no DEA-related books edited or written by a Croatian author (only book chapters), therefore it is worth highlighting the DEA-related monograph: Rabar, D. (2013) Assessment of regional efficiency in Croatia, Saarbrücken: LAP Lambert Academic Publishing, as a great contribution to Croatian DEA-literature. 
Figure 3: Number of DEA-related publications by type

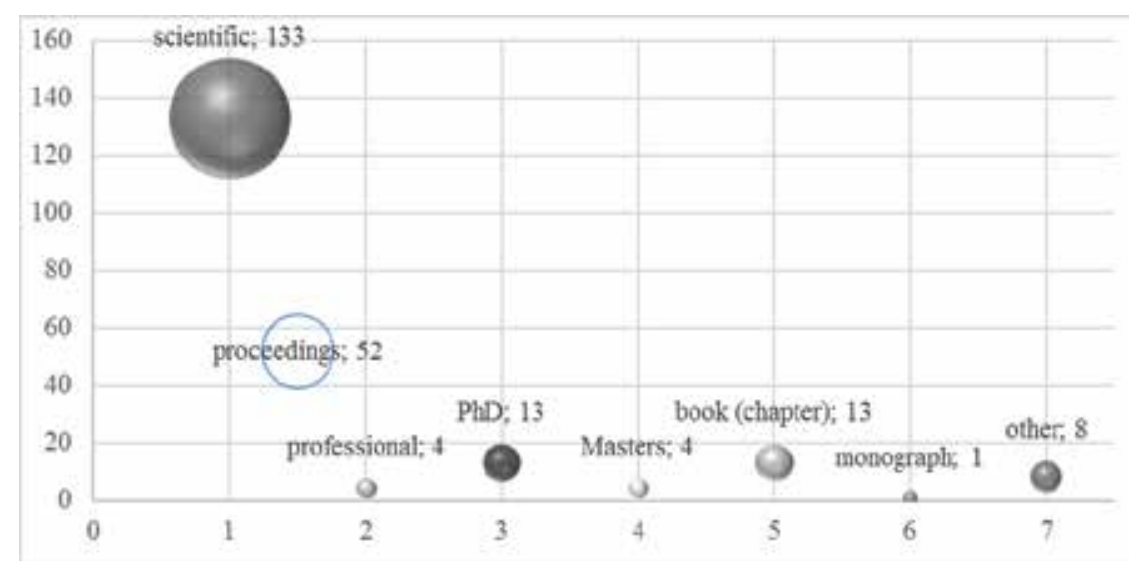

Source: authors

Additionally, for the sake of comparison, if we observe publishing in categories: journal and proceedings papers, Ph.D. thesis, Master thesis, book (chapters) and monographs and 'other', in the CROSBI bibliography in that similar period (1987 - September 2018), it can be found that $72.3 \%$ are journal papers and proceedings papers, $2.8 \%$ Ph.D. thesis, $1.9 \%$ Master thesis, $10.4 \%$ book (chapters), 1.9\% monographs and $10.8 \%$ are 'other' publications ((CROSBI [6.10.2018.]). This is depicted in Figure 4.

Figure 4: Croatian DEA bibliography and CROSBI bibliography (1987-2018) by publication categories

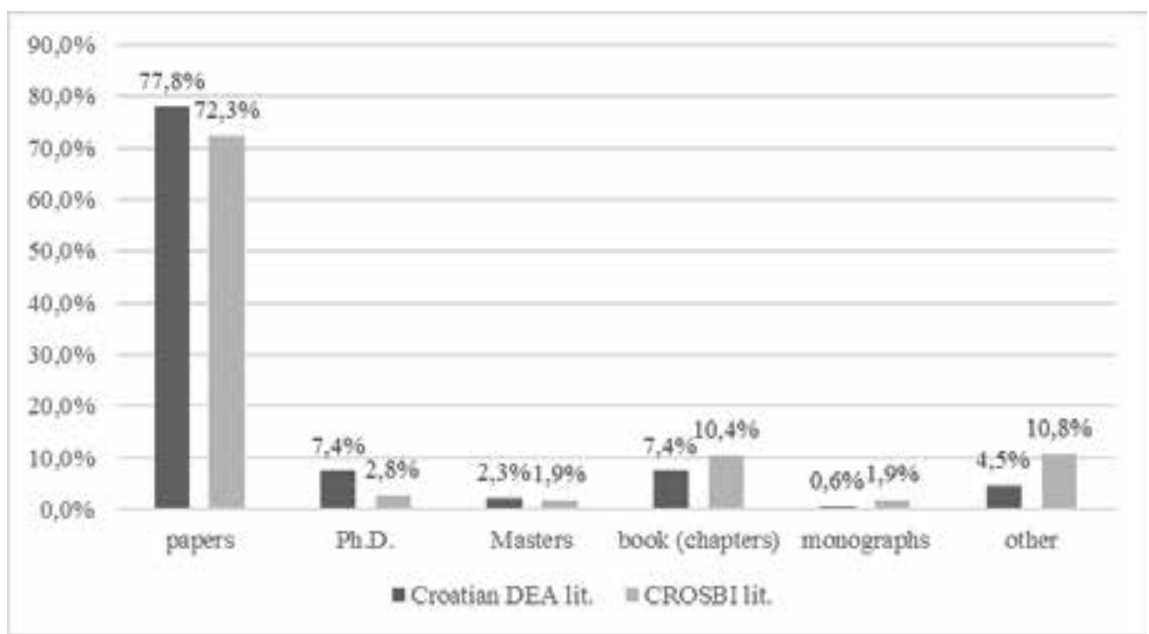


A great majority of DEA-related publications - 74\% were written and published in English (Figure 5). The rest of these publications were written and published in Croatian, including all of the Ph.D. and Master thesis, 19 scientific papers, 2 book chapters, 4 professional papers and 4 other.

Figure 5: Language and the origin of the authors of the DEA-related publications
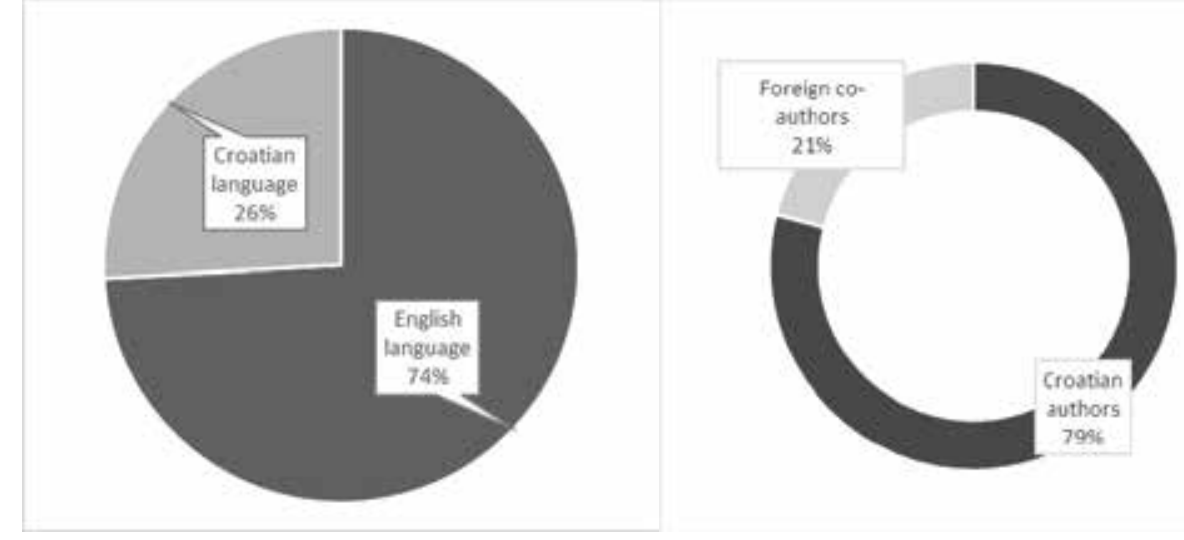

Source: authors

Regarding the authors, there are currently altogether 148 distinct authors in the Croatian DEA bibliography, out of which 117 are Croatian authors who are registered in CROSBI. This is depicted in Figure 5. Moreover, at least 38 publications were written in collaboration of Croatian authors and international authors, out of which 33 are scientific articles. Most of the international collaborations were established by Neralić, who co-authored 22 papers with international authors. Foreign co-authors come mostly from institutions from Slovenia, China, USA, and Germany.

Most of the publications in Croatian DEA bibliography have one (35.8\%) or two $(37.5 \%)$ authors, as presented in Figure 6. The largest number of authors per publication is 6 . The average number of authors per publication is 2.01 . If we observe only journal papers, then $24.8 \%$ of the papers have one author and $43.8 \%$ have two authors. The average number of authors per journal papers is 2.18. For the sake of comparison, the international average number of authors per DEA-related journal paper is 2.6 , with only $17 \%$ of the papers written by a single author, $35 \%$ by 2 authors and $29 \%$ by three authors (Emrouznejad and Yang, 2018). Evidently, there is much more collaboration between scientists on the international level and these results suggest that Croatian authors could put more effort to improve their collaborations and networking. 
Figure 6: DEA-related publication (in \%) per number of authors

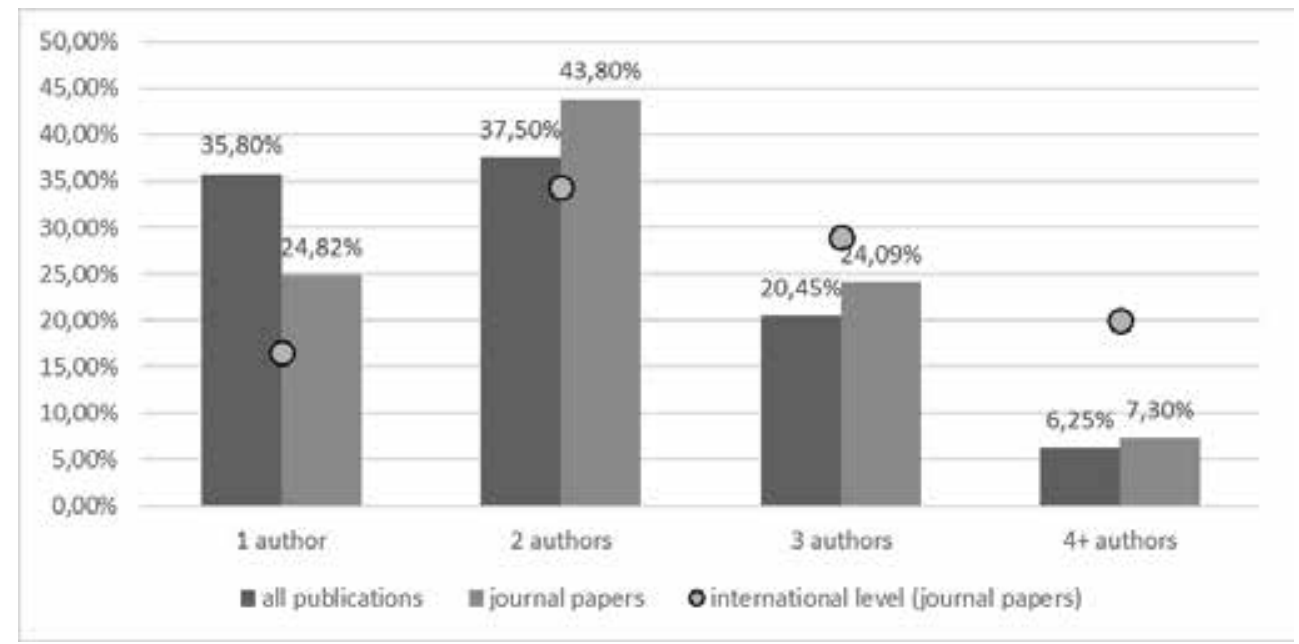

Source: authors

Further, we did the analysis regarding the Croatian authors. We observe that 74 out of 117 (64\%) Croatian authors (co-)authored only one DEA-related publication. 14 authors have two DEA-related publications, and only 13 authors have 5 or more publications. This is shown in Figure 7. In addition, we calculated that the average number of all DEA-related publications for Croatian authors is 2.56, but if we observe only journal papers, then the average drops to 2.34 papers per author.

Figure 7: Number of authors by number of DEA-related publication

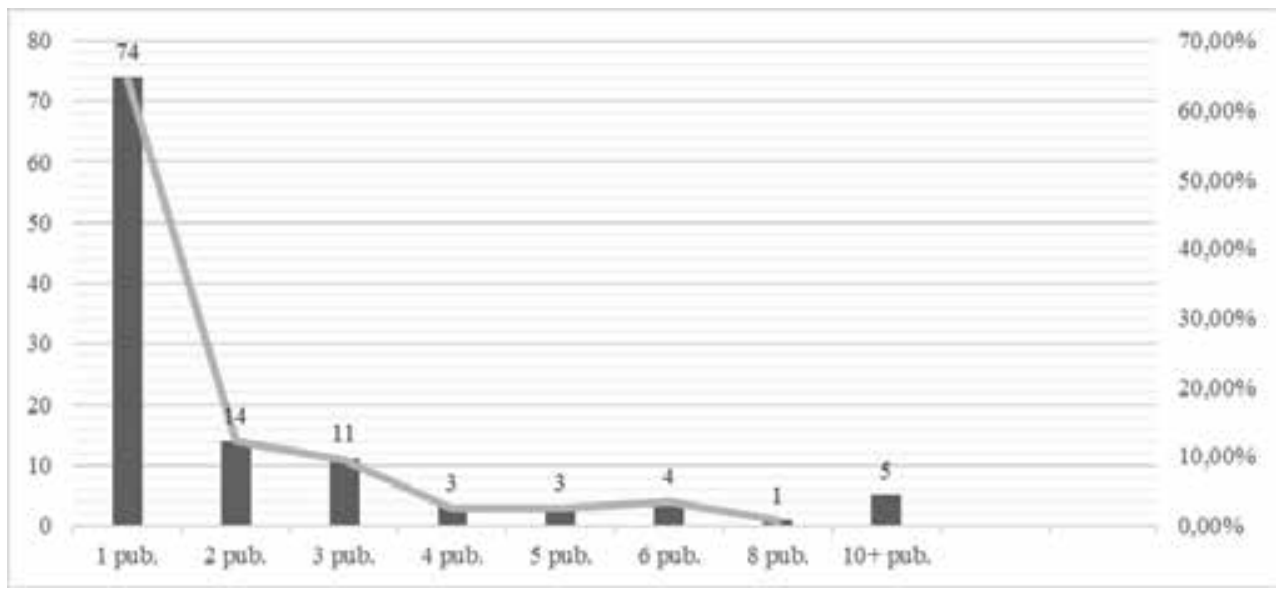

Source: authors 
The first 10 Croatian authors with the largest number of DEA-related publications are shown in Figure 8. The largest number of publications per author is 42 (authored by Neralić). Since the number of publications included in WoS citation base is an important metric for author's scientific productivity in Croatian science, we investigated the number of DEA-related publications included in WoS citation base for these first 10 authors. This data is shown also in Figure 8, where we notice that Rabar, D. has the greatest number of DEA-related publications included in WoS (8).

Figure 8: Number of total and WoS-cited DEA-related publications by author

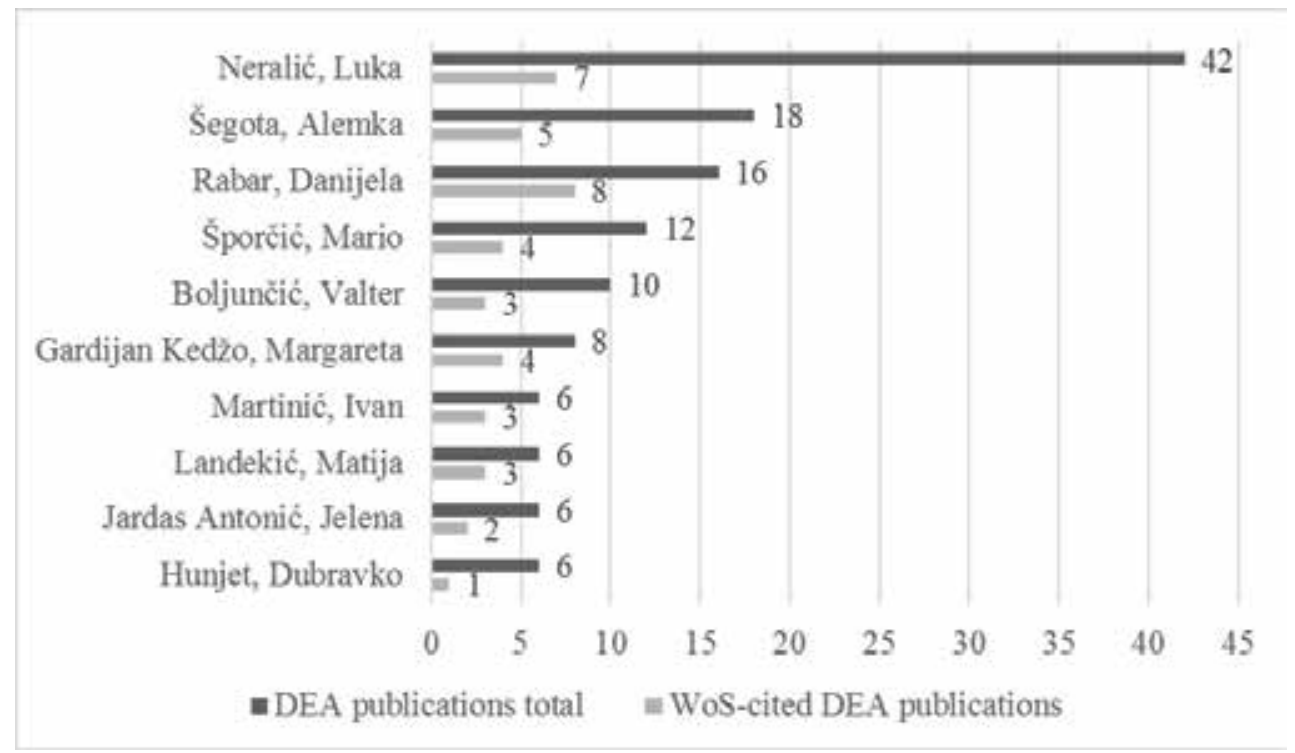

Source: authors

The distribution of publications by the number of pages is shown in Figure 9 . This analysis includes information for 172 publications since this information is unknown for 4 publications. We can see that most of the publications have 9-15 pages (45\%), what is expected given that most of the publications are journal/proceedings papers, which are usually limited to this range of pages. An average number of pages per all types of publication is 34.27 , and only for journal/ proceedings papers is 13.84 . The average for all publications is significantly greater because it includes Ph.D. and Master theses, which have from 99 to 514 pages, and from 98 to 163 pages, respectively. 
Figure 9: Number of DEA-related publications by number of pages

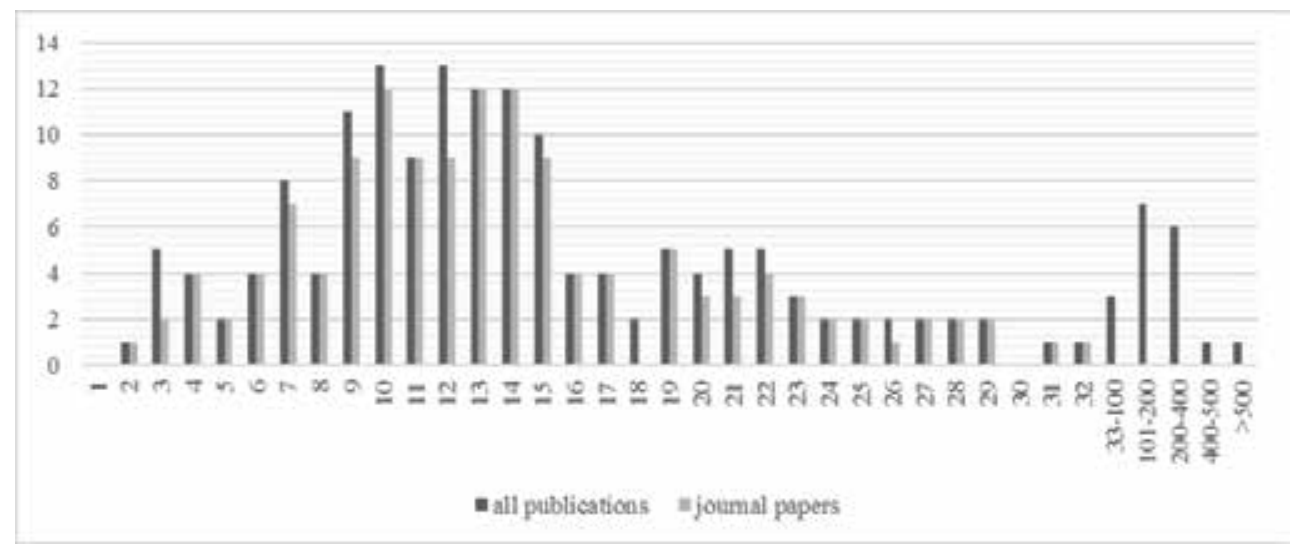

Source: authors

By analyzing the journals that published the papers included in the Croatian DEA bibliography, we were able to detect those journals that have published the greatest number of papers in our database (Table 1). The journal which appeared most frequently in our database is Croatian Operational Research Review (CRORR), the journal of the Croatian Operational Research Society, which published 10 DEA-related papers (co-)authored by the Croatian researchers.

Table 1. Journals with the largest number of publications found in the Croatian DEA bibliography.

\begin{tabular}{|l|c|}
\hline \multicolumn{1}{|c|}{ Name of the journal } & Number of DEA-related papers \\
\hline Croatian Operational Research Review & 10 \\
\hline Glasnik Matematički & 6 \\
\hline Mathematical Communications & 5 \\
\hline Economic Research (Ekonomska Istraživanja) & 4 \\
\hline Amfiteatru Economic & 3 \\
\hline Central European Journal of Operations Research & 3 \\
\hline $\begin{array}{l}\text { Proceedings of Rijeka Faculty of Economics: Journal of Economics } \\
\text { and Business }\end{array}$ & 3 \\
\hline Croatian Journal of Forest Engineering & 2 \\
\hline Data Envelopment Analysis Journal & 2 \\
\hline Economic Review (Ekonomski Pregled) & 2 \\
\hline European Journal of Operational Research & 2 \\
\hline Journal of the Operational Research Society & 2 \\
\hline
\end{tabular}

Source: authors 
We were able to detect 335 different keywords and the list of the most frequent words found in keywords is given in Table 2. As expected, the most common keywords are data envelopment analysis or DEA, followed by the keyword efficiency. However, the authors' need to be innovative with keywords made it hard for us to detect some DEA-related publications. Therefore, a suggestion for the Croatian authors in DEA would be to use relevant DEA-related keywords in the future in order to be recognized and connected with similar researches.

Table 2: Most frequent keywords of DEA-related publication

\begin{tabular}{|l|c|}
\hline \multicolumn{1}{|c|}{ Keyword } & Number of observations \\
\hline data envelopment analysis / DEA & 168 \\
\hline efficiency & 125 \\
\hline sensitivity analysis & 30 \\
\hline linear programming & 26 \\
\hline Croatia & 26 \\
\hline EU & 19 \\
\hline window analysis & 19 \\
\hline CCR & 19 \\
\hline performance & 15 \\
\hline public & 14 \\
\hline additive model & 12 \\
\hline education & 11 \\
\hline forest(ry) & 10 \\
\hline
\end{tabular}

Source: authors

The majority of the publications in our DEA bibliography are methodological papers (field of mathematics) and applications in economics and business. However, there are also significant publications from the fields of education, forestry, maritime and traffic science, electrical engineering and energetics. This shows the large applicative area of DEA. It was found that the most productive authors of methodological papers are Neralić, L. and Boljunčić, V. Applications in economics and business are numerous and dominant in the bibliography, and covered by many authors, leading with Rabar, D., Šegota, A., Neralić, L., Gardijan Kedžo, M., Jardas Antonić, J. and Hunjet, D. Applications in forestry are (co-)authored by Šporčić, M., Martinić, I., Landekić, M., Šegotić, K. and Lovrić, M. Dealing with problems in traffic science can be found in publications authored by Vojvodić, K. and Bezić, H., and then Šegota, A., Rabar, D. and some others, although the latter also other DEA-related publications: Rabar, D. mostly related to institutional and regional efficiency and $\breve{S e-}$ gota, A. in macroeconomics. Energy efficiency was considered by Borozan, . and Borozan, L., Maradin, D. and in some papers by Neralić, L. Efficiency of different aspects of education was considered in publications of Ahec Šonje, A., Obadić, A., Arbula Blecich, A. and also some other authors. Readers are invited to explore the 
bibliography (published online as an Appendix) for finding relevant authors in their research field.

Using the publications' keywords, titles and officially declared fields of research, we did a deeper analysis of the popularity of the research fields during the years of DEA in Croatian science. This revealed the tendency for a greater number of applications of DEA and less methodological advancements. Also, as shown in Figure 10, there is an increased popularity of DEA in banking, education, and energy efficiency in recent years.

Figure 10. Cumulative number of DEA-related publications within a certain research field, by year.

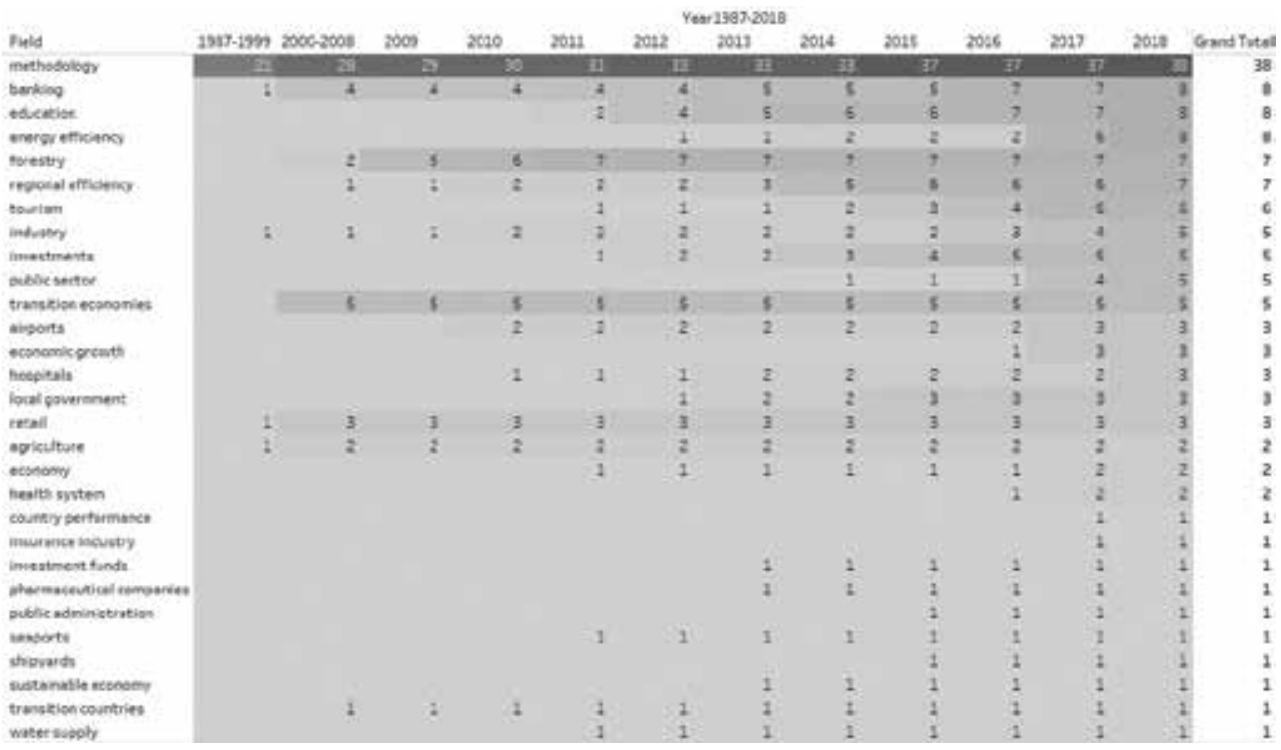

Source: authors

\section{Conclusion}

We have gathered 176 different publication related with DEA, authored or co-authored by 117 distinct Croatian researchers who are registered in Croatian scientific bibliography CROSBI or whose publications are listed in CROSBI. The created DEA database covers the period from 1987 to May 2018. The whole database is publicly available at sites.google.com/net.efzg.hr/dea. Some statistical analysis of the database was done, including the statistics per author, per publication and per publication type. The analysis revealed that Croatian science has a significant number of DEA-related 
bibliographical records and that DEA was applied for tackling many relevant efficiency issues in economics, business, forestry, education, and traffic. However, there are still great possibilities of DEA that should be explored in an effort to improve efficiency in management as well as in other various applications. The DEA-related publishing in Croatia has a growing trend, but is should speed up in order to close the gap with the global trends. We believe that this review and collection of DEA-records will facilitate scientists in finding relevant DEA literature in Croatia, initiate new research networks between Croatian (and international) scientists and ease further development of the field. A survey and an analysis of DEA-related literature in the EU countries with some comparison and ranking would be an interesting extension of this research. Despite our effort, we cannot guarantee that we have gathered all the data and that this database is complete. Therefore, we encourage all readers to inform us of any mistakes and suggestions.

\section{REFERENCES}

Ali Emrouznejad's Data Envelopment Analysis, www.deazone.com

Charnes, A. \& Neralić, L. (1987). Analiza osjetljivosti simultane promjene outputa i inputa u analizi omeđenih podataka. Zbornik radova XIV jugoslavenskog simpozija iz operacijskih istraživanja, SYM-OP-IS 1987, Herceg Novi, 1987, 87-94.

Charnes, A., Cooper, W.W. \& Rhodes, E. (1978). Measuring the efficiency of decision making units. Eur J Oper Res, 2 (6), 429-44.

Croatian Scientific Bibliography CROSBI, www.bib.irb.hr

Emrouznejad, A. \& Thanassoulis, E. (1996a). An extensive bibliography of data envelopment analysis (DEA), vol. I: working papers, 1-55. Working Paper.

Emrouznejad, A. \& Thanassoulis, E. (1996b). An extensive bibliography of data envelopment analysis (DEA), vol. II: journals papers; 1996., 1-21. Working Paper.

Emrouznejad, A. \& Thanassoulis, E. (1997). An extensive bibliography of data envelopment analysis (DEA), vol. III: supplement vol. 1., 1-24. Working Paper 258.

Emrouznejad, A. \& Yang G.-1. (2018). A survey and analysis of the first 40 years of scholarly literature in DEA: 1978-2016. Socio-Economic Planning Sciences 61 (March 2018), 4-8. http://dx.doi. org/10.1016/j.seps.2017.01.008

Emrouznejad, A., Parker, B.R. \& Tavares, G. (2008). Evaluation of research in efficiency and productivity: a survey and analysis of the first 30 years of scholarly literature in DEA. Socio-Economic Plan Sci, 42 (3), 151-157. https://doi.org/10.1016/j.seps.2007.07.002

Google Scholar, scholar.google.hr

Lukač, Z. \& Neralić, L. (2012). Operacijska istraživanja. Element, Zagreb.

Mardani, A., Streimikiene, D., Balezentis, T., Zameri Mat Saman, M., Md Nor, K. \& Meysam Khoshnava, S. (2018). DEA in Energy and Environmental Economics: An Overview of State-ofthe-art and Recent Development Trends, Energies, 11 (8). https://doi.org/10.3390/en11082002

Portal of scientific journals in Croatia, http://hrcak.srce.hr/

Seiford, L.M. (1994). A DEA bibliography (1978-1992). In: Charnes, A., Cooper, W.W., Lewin, A.Y., \& Seiford, L.M. (Eds.). Data envelopment analysis: theory, methodology and applications, 437-69. Boston, USA: Kluwer. https://doi.org/10.1007/978-94-011-0637-5_22 
Seiford, L.M. (1997). A bibliography for data envelopment analysis (1978-1996). Ann Operations Res, 73 (0), 393-438. https://doi.org/10.1023/A:1018949800069

Tavares, G. (2002). A bibliography of data envelopment analysis (1978-2001). RUTCOR, Rutgers University. Available at: http://rutcor.rutgers.edu/pub/rrr/reports2002/1_2002.pdf.

Web of Science, http://apps.webofknowledge.com 